\title{
DESIGN, REALIZATION AND EVALUATION OF A STATISTICS COURSE FOR PRESERVICE TEACHERS FOR PRIMARY SCHOOL IN GERMANY
}

\author{
Susanne Podworny, Daniel Frischemeier, and Rolf Biehler \\ University of Paderborn, Germany \\ podworny@math.upb.de
}

We designed and developed a statistics course "Data \& chance for primary school" that aims at developing content knowledge, pedagogical content knowledge, and technological knowledge of preservice primary school teachers. The course consists of weekly lectures where the content and the technological knowledge components are developed and of a weekly accompanying smallgroup seminar. The course is designed with statistical reasoning learning environment principles; interface tasks that bridge content knowledge and pedagogical content knowledge play a fundamental role in the course. Three topics are taught: data analysis, combinatorics, and introduction into probability via stochastic simulations. The first results-from online surveys before and after the course ( $n=189)$, evaluation of participants' written homework assignments, and a written test administered after the course-show that statistical thinking of our preservice teachers improves over time and that they show more positive attitudes towards statistics after having attended the course.

\section{INTRODUCTION}

Concerned citizens need statistical skills to be able to participate in public decision processes. First steps of the development of these skills can be set in primary school, which ranges in Germany from grades one to four (age 6 to 10). Also the so-called leading idea "Data, Frequency and Chance" (Hasemann \& Mirwald, 2012) recommends first statistical activities in primary school classrooms in Germany. Upcoming teachers must have sustainable content knowledge, pedagogical knowledge and also technological knowledge in statistics for being able to teach these aspects in primary school classes. One problem is that primary school teachers seem to have negative attitudes towards statistics and therefore seem to hesitate to implement statistical activities in primary school classroom. To educate primary school preservice teachers in statistics, Pfannkuch and Ben-Zvi (2011) have set requirements. One specific requirement is that teachers learn to use innovative tools and educational software like TinkerPlots (Konold \& Miller, 2011) to enhance statistical reasoning in primary school. These requirements create challenges not only for pupils, schools and teachers, but also for universities who educate prospective teachers. This was the starting point for us to design an innovative course "Data \& chance for primary school" and further develop it by applying research methods stemming from the Design Based Research paradigm (Cobb, Confrey, diSessa, Lehrer, \& Schauble, 2003). The course we describe in this paper has two major goals: Firstly we want to develop the content knowledge and the technological knowledge (Wassong \& Biehler, 2010) of our preservice teachers. Secondly we want to develop the pedagogical content knowledge and the technological pedagogical content knowledge (Wassong \& Biehler, 2010) of our teachers, to show them ways how to implement statistical activities with and without digital tools in primary school classrooms and also to improve the attitudes of our preservice teachers towards statistics. We will describe the design, the realization and also selected evaluation results of our course in this paper. One fundamental design idea of our course, which will also be presented in this paper, is to implement so-called interface tasks, where content and pedagogical knowledge components are combined and intertwined.

\section{DESIGN OF THE COURSE ON DATA \& CHANCE}

The course described in this paper is a compulsory semester-long course on statistics for preservice teachers for primary school at the University of Paderborn, Germany. The preservice teachers, most of them studying in their fourth semester, have gained pre-knowledge in statistics from secondary school, but they have not attended a university statistics course. Therefore, they do not have pedagogical nor technological statistical knowledge and have not used TinkerPlots. Throughout the whole course "Data \& chance for primary school" we have implemented elements like "focusing on central statistical ideas", "using real and motivating data sets", "using classroom 
activities", "integrating the use of appropriate technological tools", "promoting classroom discourse" and "using assessment" according to the ideas of Statistical Reasoning Learning Environments (Garfield \& Ben-Zvi, 2008). To enhance statistical reasoning of our participants in this respect, we used innovative tools and the educational software TinkerPlots for exploring real and motivating data (Garfield \& Ben-Zvi, 2008) and for simulating chance experiments. The use of TinkerPlots has the intention to fulfill two aspects in the whole course: on the one hand our participants shall position themselves into the role of learners and use the software for investigating statistical questions in real datasets or for simulating chance experiments (technological content knowledge). On the other hand the pedagogical potential of the software as well as possibilities for teaching shall be discussed and reflected (technological pedagogical content knowledge). TinkerPlots supports learners in modeling chance experiments by its user-friendly sampler instead of applying complex formulas in combinatorics to calculate the probabilities of specific events. This instance and the use of TinkerPlots also make complex and interesting questions accessible to younger students at primary school (and also to students as preservice teachers).

The classroom discourse and the development of content knowledge and pedagogical knowledge were promoted via cooperative learning environments and methods like think-pairshare (Roseth, Garfield, \& Ben-Zvi, 2008). Whereas the lecture is supposed to develop the statistical content and the technological content knowledge, the seminar is supposed to deepen the statistical pedagogical content and pedagogical technological content knowledge. Another goal is to build bridges between content knowledge and pedagogical knowledge. The bridge between those ideas is realized by working on so-called interface tasks (we will describe an example activity in this respect below). For formative assessment we used cumulative portfolios (Stratmann, Preussler, \& Kerres, 2009) where our participants had to document their homework, their activities during the seminar, their project works and the regular reflections they were supposed to do. To balance the three fundamental characteristics of the course "Learning activities", "Course learning outcomes" and "Assessment" we used the constructive alignment approach of Biggs (1996). All three characteristics are in relation to each other and all three characteristics have to be balanced in the setting of constructive alignment. In Table 1 we give details on the constructive alignment facets of our course, connecting "Course learning outcomes", "Learning activities" and "Assessment". In this table the "a" component (short: Comp.) refers to content and technological content knowledge components and the "b" component refers to pedagogical content knowledge components of our course.

Table 1: Constructive alignment of the course "Data \& Chance for primary school".

\begin{tabular}{|c|c|c|c|}
\hline Comp. & $\begin{array}{l}\text { Course learning } \\
\text { outcomes }\end{array}$ & Learning activities & Assessment \\
\hline $1 \mathrm{a}$ & $\begin{array}{l}\text { Analyzing and } \\
\text { interpreting data with } \\
\text { and without software }\end{array}$ & $\begin{array}{l}\text { Creating a survey, collecting data and } \\
\text { analyzing data with and without digital tools } \\
\text { Experience statistical activities on different } \\
\text { levels: enactive, iconic and symbolic, working } \\
\text { with data cards; interpretation of media } \\
\text { reports; exploring real data } \\
\text { Conducting hands-on activities and group } \\
\text { comparisons on a project }\end{array}$ & $\begin{array}{l}\text { Project reports, } \\
\text { analysis reports, } \\
\text { and weekly } \\
\text { homework as part } \\
\text { of the portfolio } \\
\text { Parts of a final } \\
\text { written test }\end{array}$ \\
\hline $1 b$ & $\begin{array}{l}\text { Pedagogical view on } \\
\text { data analysis }\end{array}$ & $\begin{array}{l}\text { Evaluating didactical literature from teacher } \\
\text { journals and reflecting its value for use in } \\
\text { classrooms } \\
\text { Analyzing textbook problems }\end{array}$ & $\begin{array}{l}\text { Analysis reports } \\
\text { as part of the } \\
\text { portfolio }\end{array}$ \\
\hline $2 \mathrm{a}$ & Combinatorics & $\begin{array}{l}\text { Experience combinatorics activities on } \\
\text { different levels: enactive, iconic and } \\
\text { symbolic, } \\
\text { Exercises on four types of urn models }\end{array}$ & $\begin{array}{l}\text { Weekly } \\
\text { homework as part } \\
\text { of the portfolio, } \\
\text { parts of a final } \\
\text { written test }\end{array}$ \\
\hline $2 b$ & $\begin{array}{l}\text { Pedagogical view on } \\
\text { combinatorics }\end{array}$ & $\begin{array}{l}\text { Evaluating didactical literature from teacher } \\
\text { journals and reflecting its value for use in } \\
\text { classroom }\end{array}$ & $\begin{array}{l}\text { Analysis reports } \\
\text { as part of the } \\
\text { portfolio }\end{array}$ \\
\hline
\end{tabular}




\begin{tabular}{llll}
\hline 3a & $\begin{array}{l}\text { Modelling and } \\
\text { simulating chance } \\
\text { experiments with and } \\
\text { without software }\end{array}$ & $\begin{array}{l}\text { Analyzing textbook problems } \\
\text { Hands-on activities and simulation of chance } \\
\text { experiments, computer-supported simulation } \\
\text { of chance experiments with TinkerPlots }\end{array}$ & $\begin{array}{l}\text { Weekly } \\
\text { homework as part } \\
\text { of the portfolio, } \\
\text { parts of a final } \\
\text { written test }\end{array}$ \\
3b & $\begin{array}{l}\text { Pedagogical view on } \\
\text { chance experiments }\end{array}$ & Analyzing textbook problems & $\begin{array}{l}\text { Analys part of the } \\
\text { asts } \\
\text { portfolio }\end{array}$ \\
\hline
\end{tabular}

\section{IMPLEMENTATION OF THE COURSE ON DATA \& CHANCE}

In the following, we will refer to our course which was realized in summer term 2016. In this summer term 211 preservice teachers for primary school participated in the course. The course covered 14 weeks with 90 minutes of lecture and 90 minutes seminar each week.

The first topic, data analysis, was the main topic of the course, as it is the most present for teaching in primary school. It lasted eight weeks. The starting point was looking at curricula and national standards for data analysis in primary school for establishing knowledge of curriculum. Another aspect was to experience the entire PPDAC-cycle (Wild \& Pfannkuch, 1999) with posing a statistical question arising from a statistical problem (first "P"). Planning a data collection (second "P") was the next step, followed by the data collection itself ("D") and the analysis of the data ("A"). Final conclusions ("C") and interpretations of the findings were the last step, which had to be documented in a report. Creating and interpreting different graphical displays for uni- and bivariate data with and without software was another course learning goal, as a combination of content and technological content knowledge. To develop the pedagogical content knowledge we applied the think-pair-share method and asked the participants to analyze and reflect teaching materials (tasks for pupils on primary school, work sheets, text books, articles of teacher journals). At first, they worked on their own, and then discussed the implementation of such activities in primary school in pairs; afterwards, the discussion took place in the whole group. The idea was to develop the pedagogical content knowledge of the participants by discussing the activities and implications and consequences together. For analyzing textbook problems, four aspects were discussed with regard to future pupils solving this problem. 1. What prerequisites are necessary to work on the problem? 2. What are possible learner's solutions? 3. Which challenges may arise? 4. Which learning goals are supposed to be fulfilled with the work on this problem? Another fundamental aspect of the data analysis section of our course was comparing groups. To put together many aspects (PPDAC cycle, use of TinkerPlots, analyzing real data) of the data analysis section of our course, a project on frog long jump was implemented at the end of the first topic (see next section). The use of TinkerPlots and its reflection from a pedagogical point of view was a continuous aspect of this topic.

The second topic (combinatorics) was taught for three weeks. Four urn models for conducting combinatorics tasks were introduced: draw with or without replacement, with or without regard to the order. Tasks for implementation in primary school were conducted with concrete objects (like colored tinker blocks and cubes), on an iconic level and with symbols as learning activities. Reading and discussing articles from teacher journals on the implementation of a classroom sequence on combinatorics in grade two and four was the connection between content and pedagogical knowledge. A report on these analyzes was assessed as part of the portfolio.

Since the notion of frequentist probability is a topic which has to be taught in primary school, we also introduced our participants to probability theory. This last topic on modeling and simulating chance experiments lasted for four weeks. This topic was mainly meant to introduce some background knowledge on probability theory, and to introduce the notion of frequentist probability and computer-based simulations as an informal way to solve probability problems. To sustain students' knowledge on the accuracy of simulations, the law of large numbers together with the so-called $1 / V_{n}$ law was taught. This law predicts on the one hand the interval where the relative frequency of an event is expected with $95 \%$ probability, if the probability $\mathrm{p}$ is known. On the other hand, the law allows inferences about the unknown probability $p$, when a relative frequency $h_{n}$ of an event was observed. This was communicated informally as a kind of intuitive $95 \%$-confidence 
interval, $h_{n} \pm 1 / \sqrt{ } n$, for the unknown probability $p$. A further goal of this topic was to develop technological content knowledge for simulations with TinkerPlots and also technological pedagogical content knowledge so that the preservice teachers can use TinkerPlots for demonstration purposes in classroom. Another goal was to enable participants to view simulations as one way to solve probability problems without calculations. This was reflected from a pedagogical point of view and textbook problems were analyzed and discussed.

\section{BRIDGING CONTENT AND PEDAGOGICAL CONTENT KNOWLEDGE: AN INTERFACE TASK}

In the following we present one example activity, from the end of the data analysis section of our course. We have adapted the frog-task from Eichler \& Vogel (2013) in a way, that it might be regarded as a so-called interface task combining statistical content knowledge and pedagogical content knowledge components. Translated instructions appear in Figure 1.

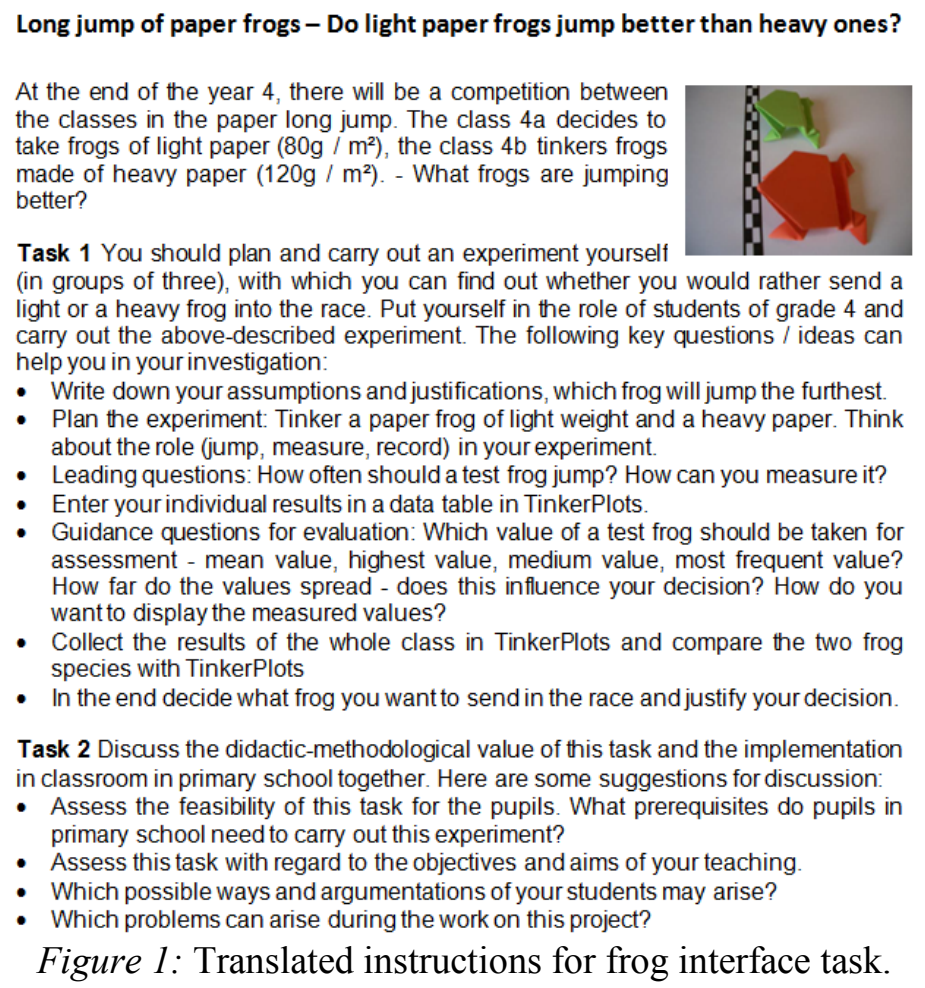

From the content knowledge perspective, students can apply the whole PPDAC cycle on their own in this activity. So at first the participants start with a statistical problem ("In which way do light frogs jump better than heavy ones?" - first "P") and can tinker their own frogs from light and heavy paper and can plan their data collection (second "P"). Then they conduct the experiment ("D") and collect frog long jump data of their group which they document and analyze with the help of TinkerPlots ("A") and then can also collect the data of the whole course in TinkerPlots. The analysis of the data leads to group comparisons and also to statistical inferences (whether the findings can be generalized for all paper frogs). Finally the preservice teachers can derive conclusions from their analysis ("C") and can answer their question posed at the beginning of the cycle. In task 2, the participants are asked to apply the pedagogical content knowledge they have gained so far and to reflect on the didactic-methodological value (feasibility, prerequisites of pupils, learning goals, possible solutions and possible problems) of the project.

Work on this project was done in teams of three. Two sessions of 90 minutes were dedicated to the project. In the first session, the PPD phases were followed, and in the second phase the AC phases took place together with discussions and reflections in plenum of pedagogical issues. In total 187 students (70 groups) worked on the frog task project. 65 of the groups delivered satisfactory project reports in their portfolios: they planned and conducted their experiment traceably, collected data on their own, and analyzed the data in TinkerPlots. 


\section{EVALUATION OF THE COURSE}

The evaluation of our course held in the 2016 summer term has been done in regard to two components: On the one hand, we have assessed the content knowledge, the pedagogical content knowledge and also the technological content knowledge in the cumulative portfolio as we have pointed out in Table 1. As data we collected the homework, the analysis reports, the project reports. All three components were part of the cumulative portfolio. Furthermore, we administered a final test at the end of our course. In the following we will only refer to the homework quality of our participants. Table 2 shows the performance of the participants in the three branches "data analysis", "combinatorics" and "chance experiments" and the total performance. Homework was graded by "+" for a good performance, "o" for an acceptable performance, or "_" for a poor performance. Table 2 gives an overview of students' performances on homework (note that homework was always about content and/or technological knowledge).

Table 2: Rating of homework in the cumulative portfolios.

\begin{tabular}{llll}
\hline Topic & Rated as “+” & Rated as “o" & Rated as “-” \\
\hline Data analysis & 0.69 & 0.18 & 0.13 \\
Combinatorics & 0.73 & 0.06 & 0.21 \\
Chance experiments & 0.69 & 0.12 & 0.19 \\
Total & 0.70 & 0.14 & 0.16 \\
\hline
\end{tabular}

As we can see in Table 2, 70\% of all homework sheets were rated as "+" and 14\% were rated as "o". So in total $84 \%$ of the homework sheets were rated at least as "acceptable". We see slight differences between the performances in the three branches, but in summary we can say, that student performance was good. Analysis of the other data we have collected provide a similar impression: 182 of $187(97 \%)$ analysis reports and project reports as part of the portfolios were satisfactory. The final test was passed by 191 of 211 students $(90.5 \%)$.

To evaluate the attitudes of the participants towards statistics and towards implementing statistical activities in primary school classrooms, we asked participants to fill out a short online survey before attending the course and after attending the course. The participation was voluntary and in total 189 participants took part in the pre- and post- survey. The first item ("I feel competent to teach statistics in primary school.") aims at the self-concept of the preservice teacher whether he/she feels competent to teach statistics in primary school. The second item ("I think statistics is interesting.") deals with the attitude of the preservice teacher towards statistics in general (whether he/she finds statistics interesting). The third item ("I feel unsure when dealing with statistical problems.") covers the anxiety which might be present for preservice teachers when dealing with statistical problems. We asked our participants to rate these items on a Likert scale with four values from "fully applies" to "does not apply at all".

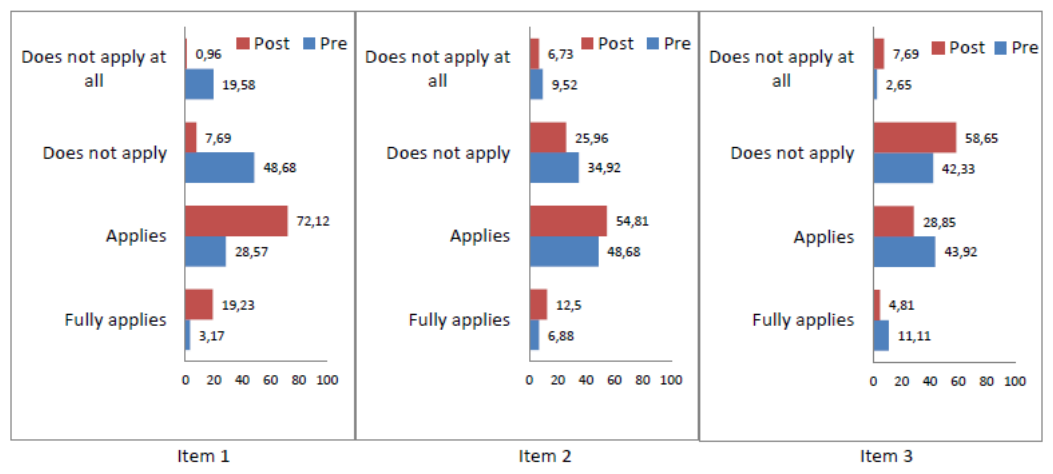

Figure 2: Student evaluation of the course (pre-evaluation survey: blue bars; postevaluation survey: red bars).

In Figure 2 we see the frequency distributions of the answers of the participants before the course (blue bars) and after the course (red bars). More than $90 \%$ of the participants feel competent 
after attending the course to teach statistics in primary school, compared to a little less than $30 \%$ who felt this way in the beginning of the course. Concerning the uncertainty, to deal with statistical problems (item 3), there are about $66 \%$ of participants, for whom this does not apply or does not apply at all after attending the course. In the beginning, this rate was only about $45 \%$.

These three items and the analysis of the other data (homework, analysis reports, project reports and final tests) show exemplarily the contribution of the course "Data \& chance in primary school" in regard to the development of the content, pedagogical and technological knowledge and in regard to the attitudes towards statistics of our participants and let us assume that the preservice teachers consider implementing statistics in the classroom in primary school in their future career.

\section{FINAL REMARKS}

As a whole, the course "Data \& chance in primary school" is well established at the University of Paderborn. Due to the design-based iterations, the course design and the activities are improved continuously. The evaluation shows that participants of the course show a better attitude towards statistics and also show a greater willingness in implementing statistics in classroom in primary school. Very positive examples of an implementation of statistical activities in primary school classrooms can be found-for example, in two Bachelor theses whose authors both participated in the course. The first student has designed, realized and evaluated a series of lessons teaching data analysis and group comparisons in grade 4 and showed that even at this very early age it is possible to implement activities in primary school to enhance statistical reasoning and to lead young students to pre-formal concepts like modal clumps for group comparisons. The second student has concentrated on the probability part and has designed, realized and evaluated a teaching unit for developing statistical reasoning in regard to comparing chances of experiments like the throw of two dice in grade 4.

\section{REFERENCES}

Biggs, J. B. (1996). Enhancing teaching through constructive alignment. Higher education, 32(3), 347-364.

Cobb, P., Confrey, J., diSessa, A., Lehrer, R., \& Schauble, L. (2003). Design experiments in educational research. Educational Researcher, 32(1), 9-13.

Eichler, A., \& Vogel, M. (2013). Leitidee Daten und Zufall (2 ed.). Heidelberg, Germany: Springer Spektrum.

Garfield, J., \& Ben-Zvi, D. (2008). Developing students' statistical reasoning. Connecting Research and Teaching Practice. Dordrecht, The Netherlands: Springer.

Hasemann, K., \& Mirwald, E. (2012). Daten, Häufigkeit und Wahrscheinlichkeit. In G. Walther, M. van den Heuvel-Panhuizen, D. Granzer, \& O. Köller (Eds.), Bildungsstandards für die Grundschule: Mathematik konkret (pp. 141-161). Berlin, Germany: Cornelsen Scriptor.

Konold, C., \& Miller, C. (2011). TinkerPlots 2.0 [Computer software]. Emeryville, CA: Key Curriculum Press.

Pfannkuch, M., \& Ben-Zvi, D. (2011). Developing teachers' statistical thinking. In C. Batanero, G. Burrill, \& C. Reading (Eds.), Teaching statistics in school mathematics-challenges for teaching and teacher education (pp. 323-333). Dordrecht, the Netherlands: Springer.

Roseth, C. J., Garfield, J. B., \& Ben-Zvi, D. (2008). Collaboration in learning and teaching statistics. Journal of statistics education, 16(1), 1-15.

Stratmann, J., Preussler, A., \& Kerres, M. (2009). Lernerfolg und Kompetenz: Didaktische Potenziale der Portfolio-Methode im Hochschulstudium. Zeitschrift für Hochschulentwicklung, 4(1), 90-103.

Wassong, T., \& Biehler, R. (2010). A model for teacher knowledge as a basis for online courses for professional development of statistics teachers. In C. Reading (Ed.), Data and context in statistics education: Towards an evidence-based society. Proceedings of Eighth International Conference on Teaching Statistics (ICOTS8, July, 2010), Ljubljana, Slovenia. Voorburg, The Netherlands: International Statistical Institute.

Wild, C. J., \& Pfannkuch, M. (1999). Statistical thinking in empirical enquiry. International Statistical Review, 67(3), 223-248. doi:10.1111/j.1751-5823.1999.tb00442.x 